\title{
¿Vecinos y ciudadanos?: la teoría de los sectores populares desde una "cartografía industrial" de la Buenos Aires de entreguerras
}

Neighbours and citizens? An approach to the popular sector's theory from an "industrial cartography" of the between wars Buenos Aires

\section{Mauro Ignacio Greco mauroigreco@yahoo.com}

http://orcid.org/0000-0003-0229-2302

Instituto de Investigaciones Gino Germani; Universidad de Buenos Aires/ Universidad Nacional de La Pampa/ Consejo Nacional de Investigaciones Científicas y Técnicas (Argentina)

\section{Resumen}

La "teoría de los sectores populares" postula, hacia la Buenos Aires de comienzos de siglo pasado, el desdibujamiento del sujeto clase obrera y la conformación de un mosaico urbano 
híbrido, sin clivajes de clase claros, con su correlato en la escenografía urbana: barrios habitados por "sectores populares" más que por clase obrera o patrones oligarcas. La Ley Saenz Peña, el ascenso del yrigoyenismo, la expansión del Estado benefactor-clientelar y la posibilidad de ascenso social, se encontrarían entre los determinantes. La idea de ciudadanos y vecinos sería una materialización de esta modificación. En este trabajo volveremos sobre una serie de hechos históricos que permiten, al menos, poner en tela de preguntas aquella "imagen de ciudad": Ia Buenos Aires del último cuarto del siglo XIX a la primera quincena del siglo XX; las semanas "roja" y "trágica"; y la huelga de la construcción de enero de 1936. Estos trabajos, sumado a una "cartografía industrial" de la Buenos Aires de entreguerras, nos permitirán volver sobre la categoría de vecino, una noción que nos acompaña desde tiempos coloniales.

Palabras clave: Vecinos; sectores populares; clase obrera; Buenos Aires.

\section{Abstract}

The "popular sector's theory" postulate, towards the last century beginnings' Buenos Aires, the dilution/blurring of the working class subject and the construction of an hybrid urban patchwork, without clears class' divisions, with his consequent correlation in the urban scenography: living neighbourhoods more for "popular sectors" than working-class members or oligarchic bosses. The Saenz Peña's law, the yrigoneyism's grown, the welfare-prevailed State and the social climbing possibility would be among the reasons. The citizen and neighbours ideas would be a materialization of this change. In this paper we are going to work on a historical events' range that permits, at least, formulates some questions to that "city's image": the Buenos Aires last fourth nineteen century's to his first twenty century's fortnight; the "red" $y$ "tragic" weeks; and the January 1936's construction strike. Those works, in addition to an "industrial cartography" of the between war's Buenos Aires, will lead as to analyse the neighbour category, one notion that us from colonial times.

Keywords: Neighbors; popular sectors; working-class; Buenos Aires. 
Este trabajo se propone un acercamiento a la "teoría de los sectores populares" a partir de la "cartografía industrial" (Camarero, 2007: 23) de la Buenos Aires de entreguerras (1). Lo que se intentará aquí será revisitar esta teoría, que realiza un ahínco especial en el concepto de vecino, a partir de ciertas investigaciones sobre la Buenos Aires -"corazón económico, político y cultural del país" (Camarero, 2007a: 39)- de entreguerras, pero también sobre su precedente inmediato: la Buenos Aires de fines del siglo XIX a comienzos del siguiente.

En esta dirección, a partir del modo en que es leída por algunos de sus lectores críticos, primero se describirán los puntos fundamentales de la citada teoría, así como, a través de uno de sus herederos teóricos, el modo en que se implementa en un caso particular de análisis. Luego, antes de entrometernos en la cartografía industrial de la Buenos Aires de entreguerras, repasaremos una serie de trabajos que describen y analizan una de las principales condición de producción de aquella ciudad: la polis inmediatamente anterior de fines del siglo XIX a la segunda década del siglo XX. Finalmente, sumergidos en la citada cartografía, repasaremos la "imagen de ciudad" (Huyssen, 2007: 189) que ella nos brinda en contraste con la teoría de los sectores populares (de aquí en adelante TSP), y qué consecuencias se derivan para la idea de vecino. Por último, esbozaremos unas palabras finales a modo de cierre tentativo del trabajo.

\section{La teoría de los sectores populares y sus alcances y limitaciones}

La teoría de los sectores populares será abordada aquí desde el punto de vista de una "cartografía industrial". Camarero se propone un "balance de la interpretación" (2007a: 36) de la teoría de los sectores populares. En el marco del resumen de sus "planteos fundamentales" (Ibídem: 37), el autor resalta la postulación, hacia la Buenos Aires de los veinte y parte de los treinta, de una "escasa conflictividad" en la que germinó una "cultura popular basada en una experiencia barrial interclasista" generada por "sectores populares urbanos" de "bordes imprecisos" (Ídem). Se produce, entre las dos guerras mundiales, la conformación de una "identidad popular, conformista y reformista", la cual explicaría la ausencia de importantes conflictos laborales hasta el 36 , cuando la identidad popular recobró su "carácter proletario y sindical", lo que se tornaría evidente con el peronismo. Camarero reconoce a la TSP la visibilización de un nuevo actor: "los 'sectores populares urbanos", un refrescamiento de la "historia de las clases subalternas en la Argentina" (Ídem) y la propuesta de debate en torno a términos como "clase, conciencia e identidad de clase" (Ibídem: 38). Sin embargo, objeta "cierta caricaturización del marxismo" y lo que denomina "límites, defectos y distorsiones" que 
ubica en la "vaguedad y opacidad" de una categoría como sectores populares urbanos. En su lugar, propone la hipótesis de un "perfil menos animado por la expectativa de la integración social" (Ídem).

Luciano de Privitellio, en su trabajo sobre "sociedad y política en la Buenos Aires de entreguerras", comienza afirmando que su investigación se ubica "en la intersección de estos dos procesos: entre la sociedad y la política, entre la suburbanización y el reformismo, entre el vecino y el ciudadano" (2003: 18, cursivas del autor). De esta forma, ya desde la auto-ubicación conceptual, vemos la herencia de la TSP en la analogía entre política y reformismo en la Buenos Aires de entreguerras. Para aquellos fines, el autor retoma la tradición municipalista española donde el vecino-votante eran aquellos "ciudadanos mayores de edad que pagaran patente comercial o industrial (...) o ejercieran una profesión liberal, y los extranjeros que contribuyeran por más de 50 pesos fuertes anuales" (Ibídem: 24). Sin embargo, el vecino no compartía "universo conceptual" (Ibídem: 26) con el ciudadano, ya que aquel no estaba asociado al principio de igualdad política, "por el contrario era lícito y conveniente que en las comunas se expresaran de modo transparente las desigualdades propias del mundo social" (Ídem). De esta manera, amparados en su condición de contribuyentes votantes distinguidos, los vecinos podían ejercer función policial sobre las viviendas -por lo general de no vecinos no electores- de su circunscripción que hubieran sido denunciadas -por "al menos tres vecinos abonados" (Ibídem: 28)- por no cumplir las normas higiénicas estipuladas, tal establecía la Ley orgánica municipal de 1882. Como vemos, las relaciones entre vecindad, denuncismo y policía eran estrechas. Sin embargo, sostiene de Privitellio, con su federalización la ciudad creció exponencialmente perdiendo su fisonomía aldeana anterior, creándose redes de sociabilidad antes inexistentes. De la mano de ello, la "concepción vecinal del barrio" (Ibídem: 32) se difunde hacia fines de la segunda década del siglo XX, parte del periodo de entreguerras. Junto a su difusión, dice de Privitellio, marchan también el ideal del progreso y la movilidad social ascendente, "una visión progresista que se convirtió en componente básico de la cultura política y social de la ciudad" (Ídem). Aquí estamos donde partimos, y en el terreno donde nos moveremos, en la TSP de Romero y Gutiérrez que el autor cita en la siguiente página en torno a tal categoría. De esta manera, al trabajar el pleito con la Compañía Hispano Argentina de Electricidad (CHADE) durante la intendencia de Mariano de Vedia y Mitre (Ibídem: 150) -único conflicto relevado en el lapso recortado por el libro-, se encuentra, a partir de la visibilidad otorgada a las Sociedades de Fomento (105-147), la importancia brindada a las figuras del "vecino y el ciudadano", dos materializaciones entre otras de la STP. Sin embargo, esta "imagen de ciudad" (Huyssen, 2007: 189) halla su relativización a través de la "cartografía 
industrial" (Camarero, 2007) de la misma. Antes de proceder a su descripción, nos enfocaremos en una de las principales condiciones de producción de esa ciudad, ya sea descripta como "democrática, pluralista y progresista" (Camarero, 2007a: 58) o bien, como sostiene este autor, menos afecta a la conciliación: la Buenos Aires de fines de s. XIX y primera década del siglo siguiente.

\section{La ciudad $(y)$ letrada}

Ricardo Falcón brinda un panorama de la Argentina decimonónica del último cuarto de siglo:

En 1869 había en el país 54.760 casas de ladrillos, de las cuales, 47.023 tenían azotea y 7.737 techos de metal, tejas o zinc. En 1895 el total de casas de material era de 236.237, lo que implicaba un aumento del 431\%. De ellas 111.908 eran de azotea y 124.329 con techados de otro tipo. Además había 3.312 edificios de más de un piso, construidos en su mayoría en la Capital y en las provincias de Buenos Aires y de Santa Fe (1984: 65).

En menos de veinte años, se percibe el aceleradísimo crecimiento urbano que De Privitellio también registra para el periodo de entre-guerras, centrado en tres zonas geográficas, lo que asimismo justifica la representatividad de su estudio para una pintura más general. A dieciséis años de la batalla de Caseros y trece de la primera redacción constitucional, se registra el primer censo que tendrá una explosión por cuatro dieciséis años después. Para 1895 resulta ya notoria la presencia izquierdista representante del movimiento obrero en la ciudad.

laacov Oved (1978: 72) sistematiza la existencia de grupos como el Grupo Juventud Anarquista de Almagro -fundado en 1899-, Los Ácratas de Barracas del Norte (Ibídem: 104), El Libertario de Almagro, y Tierra y Libertad de Constitución (Ibídem: 72), pero también la presencia izquierdista urbana a través de la Casa del Pueblo en Callao 353 y la Sociedad Ligure en Suarez 776 (La Boca), donde se desarrollaría el primer Congreso de la Federación Obrera Argentina (Ibídem: 163) (2). También, la presencia socialista con su centro en México 2070 paraje de diversísimas organizaciones y funciones en los siguientes cuarenta años- (Oved, 1978: 170) y una de las filiales del Partido Socialista en Barracas Norte (Ibídem: 88), lo que, en el caso del barrio, da cuenta de su relevancia sobre todo subjetiva dada su subdivisión. Juan Suriano (2001: 46) destaca la actividad de seis grupos en la Buenos Aires de 1897: los cuatro ya nombrados, y Luz y Vida en Montevideo entre Charcas y Santa Fe de los foguistas de La 
Boca, y Nueva Luz en Villa Crespo. Asimismo, para 1902, resalta la existencia de veintidós centros como la Casa del Pueblo -en Callao 353 desde 1899 a 1902 (Ibídem: 48), en Cuyo (hoy Sarmiento) 1557 por breve lapso, en Charcas 1009-1049 desde abril de mismo año (Ibídem: 50) - en toda la Capital (Ibídem: 51). Con la exclusiva presencia por entonces del anarquismo y el socialismo, las izquierdas se difuminaban por la ciudad en construcción, con asiento en los vecindarios obreros -Barracas, La Boca, Constitución- aunque no exclusivamente: ejemplo de ello es el relevamiento de Suriano (Ibídem: 53) de la presencia anarquista en Palermo, Villa Urquiza y -alejado por entonces- Belgrano, barrios que, si bien no poseían la fisonomía de clase media o clase media-alta actual, tampoco resultaban zonas clara y distintamente obreras.

La disputa entre anarquistas organizadores y antiorganizadores, y principalmente la acumulación originaria socialista pre-Juan B. Justo, nos brindan otra clave de acercamiento a las condiciones de producción de la Buenos Aires de entreguerras, sea esta descripta como el universo de la democratización del vecino y la generalización de la ciudadanía, o como un mundo donde disputas, conflictos y enfrentamientos todavía tenían lugar. Horacio Tarcus (2007: 274), en su estudio sobre las recepciones de Marx en el socialismo argentino de fines de siglo XIX, recuerda el primer congreso, en 1891, de la recientemente fundada Federación Obrera en el local de la Unión Suisse, San José 7. Esta nueva Federación, de la que era órgano de prensa El Obrero, se instaló primero en Independencia 1252, casa de Augusto Kühn, uno de sus más destacados dirigentes, y luego en Rincón 764, sede del Verein Vorwats (Ibídem: 269), parte histórica de la acumulación originaria socialista prejustiana y de las recepciones de Marx en la Argentina de hace más de un siglo. En 1894, ante el eclipse de la primera Federación por la crisis económico-especulativa de 1890 , se instala la Segunda Federación Obrera en Ayacucho 1394, local de la Sociedad de Herreros y Anexos (Ibídem: 279). Un año antes, 1893, suceden algunos acontecimientos de importancia para el socialismo argentino de fines de siglo XIX: la segunda etapa de El Obrero con su redacción en Estados Unidos 842 (Ibídem: 289), y la experiencia de El socialista. Órgano del Partido Obrero cuyas "agencias de suscripción nos dan una idea de sus sostenedores y de su radio geográfico" (Ibídem: 291); el ya citado domicilio particular de Kühn, el de Carlos Mauli (Chile 2181), el de Mariano García (Lorea 790) y el de Isidro Solano (Armenia 622, entre Solís y Entre Ríos). Disensos, explicados por Tarcus en términos fraccionales y -retomando a Freud- del narcisismo de la pequeña diferencia, dará lugar a otro de los sucesos importantes del 93: la creación del Partido Socialista Obrero Internacional (PSOI), cuyo local estaba en Armenia 622. Asimismo, crecida en torno a El socialista, nace la Agrupación Socialista de Buenos Aires - 
quizá el cuarto hecho determinante para las izquierdas argentinas de 1893-, una agrupación que, ya para el 14 de julio del 94, inaugura un local en Chile 959; luego de varias mudanzas, recién se instala en 1897 en un local propio en México 2070 en una casa construida para esos fines por el socialista alemán Christian Haupt (Ibídem: 301). Aquí comienza la historia de los variados usos de esta polifacética morada, a la que habría que sumar la historia de sus vecindades: por ejemplo la librería situada a su costado luego mudada a México 2162 y después a Corrientes 1200. La historia del socialismo como de la Buenos Aires decimonónica resulta inescindible de la cultura libresca que hegemonizaba la época.

Un ejemplo de ello es la importancia otorgada por los socialistas a la existencia de bibliotecas allí donde se organizaran y agruparan. Por ejemplo, en el recuerdo de Ángel Giménez de su visita treinta años atrás al Centro Socialista Obrero de Chile 959, aquel destacaba, además de cuadros con barbudos retratados, la presencia de un modesto "mueble con pretensiones de biblioteca" (Ibídem: 324). O, en la memoria de Gilimón del Centro Socialista Obrero de Europa (hoy Calvo) 1971 en 1895, en el marco de una nueva conmemoración del aniversario de la comuna de París, el retrato de Marx y la misma modestia amueblada del centro anterior (Ídem). Otras de las sedes de estos centros socialistas obreros urbanos y librescos fueron el Teatro Onrubia -luego Victoria- en San José y Victoria -hoy Hipólito Yrigoyen- en 1894 (Ibídem: 338), y, en 1896, el Centro Socialista en el suburbio Las Flores (hoy Flores), instalada en Caracas 650, domicilio particular de entonces de Carlos Mauli. También existieron Centros Socialistas Obreros en Barracas Norte y Barracas Sur (Ibídem: 406) y en Balvanera (Ibídem: 357). Esta articulación entre cultura libresca y despliegue urbano será retomada a continuación, de otro modo, a partir del trabajo de Dora Barrancos (2003).

Barrancos, en su investigación sobre experiencias educativas alternativas en las izquierdas de fines del siglo XIX y comienzos del siguiente, da cuenta de los sitios geográficos donde aquellos experimentos de educación no tradicional tuvieron lugar. Para fines del siglo XIX, en la sede de un Centro Socialista Obrero se instaló un Centro de Estudios, en Chile 1159 (Ibídem: 21). En la sede del Centro Socialista "Carlos Marx", Humberto I 3410, una escuela (Ibídem: 30). En la Sociedad Unión Obrera de Ebanistas y de la Sociedad Cosmopólita de Obreros Albañiles, Tucumán 3211, otra escuela (Ibídem: 35). En la "sede histórica del socialismo de principios de siglo" (Ibídem: 25), Méjico 2070, la sección obreros de la Unión General de los Trabajadores (UGT) fundó otra escuela (Ibídem: 37). Para 1903, se contaba en Barracas al sur, Belgrano 234, con una Escuela Nocturna (Ibídem 38). En el vecino barrio de la Boca se creó la Escuela Laica (Ibídem: 42) que contó con una activa participación de los vecinos de las clases populares, por ejemplo formando parte de la comisión directiva organizadora (Ibídem: 43-44). 
En el mismo barrio, en el local de los Bomberos Voluntarios de la Boca, Brandsen 567, se fundó una escuela primaria (Ibídem: 45). Ya para 1908, en el norte lindante a Palermo -por entonces alejadísimo del centro y zona de orilleros y quintas-, más precisamente en Estelco y Conessa, se creó la Escuela de Unión de Colegiales (Ibídem: 52). Para la década del veinte, la autora destaca la presencia de la sociedad Obrera en la casa histórica del socialismo y el "esplendido edificio" (Camarero, 2007: 220) de la Sociedad Luz en Barracas (Barrancos, 1991: 96). Asimismo, la existencia de las bibliotecas Edmundo de Amici en Barracas, Mariana Chertkoff en Caballito y Francisco de Cuneo en Almagro, así como el programa de bibliotecas "Ferroviarios en marcha" en Barracas (Ibídem: 98-99).

Ahora bien, más allá de la cartografía educativa-urbana, Barrancos también analiza uno de los puntos centrales del presente trabajo, la categoría sectores populares. Si bien cita a Romero y Gutiérrez al respecto de la principal promoción de las bibliotecas populares por el socialismo (Ibídem: 95), Barrancos analiza críticamente el concepto acuñado y popularizado por aquellos: la autora sostiene que le parece importante distinguir "las demarcaciones más 'estructurales' de los diversos grupos" pero sin dejar de recusar el "reduccionismo teórico" en el plano empírico, a lo cual agrega que "las vecindades sociales llevan a un aplanamiento de lo heterogéneo sobre todo en el campo de la cultura" (Ibídem: 121). Su movimiento es interesante ya que, retomando y a la vez distanciándose de la categoría sectores populares, no deja de reconocer la importancia que el análisis estructuralista mantiene, pero no por eso se excusa de señalar el reduccionismo teórico que implica insistir sólo en el concepto de clase para explicar realidades nuevas. Al mismo tiempo, no por lo anterior acuerda sin más con la idea de vecindad social, ya que esta también le resulta empobrecedora de una heterogeneidad cultural que excede los estrechos corsets de la categoría. De esta manera, manteniéndose en un entre teórico, utiliza de cerca y observa de lejos ambas nociones. Un movimiento de acercamiento-alejamiento epistemológico nada desdeñable metodológicamente.

\section{Las semanas roja y trágica}

Otro acercamiento a la Buenos Aires inmediatamente anterior a la polis progresista y reformista o bien todavía contestataria y conflictiva, nos lo brindan dos hechos fundamentales de las primeras dos décadas del siglo XX: la "semana roja" (Bilsky, 1985: 152) y la "semana trágica" (Rock, 1977; Lvovich, 2003). Bilsky analiza los sucesos del 1 de mayo de 1909 donde, ante una concentración obrera en conmemoración de un nuevo aniversario de la masacre de 
obreros norteamericanos, la Policía Federal a cargo de Ramón L. Falcón abre fuego contra la manifestación produciendo siete muertos. Al día siguiente, sin los cuerpos no entregados por el gobierno temeroso de las consecuencias de la manifestación, las fuerzas obreras se concentran en el cementerio de la Chacarita -ex campo de deportes del Colegio Nacional Buenos Aires (CNBA) -, registrándose a la noche tiroteos en Barracas (Bilsky, 1985: 151). En el cuarto día de huelga general ya decretada el 1 de mayo ante los siete asesinatos, a los cuales se suman los nuevos asesinados por la Policía Federal en el mitin del PS del 2 de mayo en Plaza Constitución, el comité de huelga convoca un acto en la misma plaza. El 9 las asambleas obreras deciden la deposición de la huelga y vuelta al trabajo, calculándose un total de veinticinco muertos del 1 a la fecha, quedando inmortalizados esos ocho días como "la semana roja" (Ibídem: 152). Un año después, ante una nueva conmemoración a la cual no dejan de agregarse motivos y banderas, se registra una manifestación "sin antecedentes" (Ibídem: 157) a cargo de los anarquistas que congrega a 70.000 personas. Un mitin en Plaza Colón, en demanda de derogación de la ley de residencia de 1902 de Miguel Cané, libertad a los presos por "cuestiones sociales" y amnistía a los desertores del también recientemente impuesto servicio militar obligatorio, decide la convocatoria a la huelga general por tiempo indeterminado para el 18. Adelantándose a la fecha estipulada, el 16 la misma ya se extiende por los barrios populares de La Boca y Barracas (Ibídem: 158). Esta etapa marcará la cresta de la ola de masividad y capacidad de movilización del anarquismo, alicaída por la represión desatada ante los preparativos organizativos del primer centenario, popularidad que recién repuntará relativamente para la década del 30 . En dos años y por varios puntos de la ciudad, se observa un nivel de conflictividad con una identidad pos-contestataria.

Otro ejemplo de ello es lo trabajado por David Rock (1977) en torno a "la semana trágica". Disparada en torno a los talleres metalúrgicos Pedro Vasena e Hijos Ltda. en Nueva Pompeya, esta huelga es declarada el 9 de enero en respuesta a los famosos "salarios de hambre y medidas policiales que acostumbraba tomar la empresa" (Rock, 1977: 172). La huelga congregó un centenar de obreros sobre Nueva Pompeya, así como también se hizo sentir notoriamente en barrios vecinos (Ibídem: 174). Al proceso de despliegue huelguístico -quema de automóviles, saqueo de un asilo de huérfanos católico, intento de robo de armas- devino el despliegue represivo, el que no se centró -notoria y sintomáticamente- en el foco de la movilización, Nueva Pompeya y sus vecindades, sino en la comunidad ruso-judía fundamentalmente habitante del barrio relativamente cercano hacia centro de Villa Crespo. La justificación fue que "formaba parte de una conspiración revolucionaria conducida por comunistas ruso-judíos" (Ibídem: 177). El despliegue represivo provocante del repliegue 
movilizador tuvo sus jornadas de apoyo por la Liga Patriótica, flamante agrupación de civiles de clase media y alta e interpelante de las "organizaciones vecinales" (Ibídem: 199) para su colaboración en la represión, en Plaza Congreso el 10 de enero, en una multitudinaria reunión a la que no dejaron de asistir legisladores conservadores y radicales (Ibídem: 180). Aquella también tendrá una destacada participación en torno de las huelgas de mediados del 19 donde otra vez llamará a la "multitud de brigadas de vecinos" (Ibídem: 199) a contribuir en el desbaratamiento de la conspiración maximalista de la que eran víctimas. Ya en el 19, comienzo del periodo entre-guerras, persisten más que se manifiestan conflictividades urbanas como la huelga a Vasena o las de los obreros marítimos.

Decíamos, sin embargo, que la concentración represiva en la comunidad ruso-judía de Villa Crespo, más que en el disparador de Pompeya, resultó notoria y sintomática. Daniel Lvovich (2003) analiza los sucesos de enero del 19 desde una perspectiva que, además de rigurosa, asimismo resulta prolífica para pensar la última dictadura argentina. Lvovich se centra en el papel del rumor y la paranoia -es decir: las emociones- de las clases dominantes argentinas en la "desproporcionada" respuesta represiva a los acontecimientos huelguísticos. Los mismos no fueron contestados en función de su peligrosidad objetiva, sino en función de su mediación por emociones como el miedo y la paranoia que agigantaron su amenaza real. Las huelgas no fueron respondidas de acuerdo a lo que ellas solamente eran, sino a lo que de ellas se sospechaba de acuerdo a los marcos subjetivos a partir de los que cuales eran interpretadas, dominados por emociones paranoiquenates como el miedo y la inseguridad, potenciadas por la falta de contacto -o contacto exiguo- que agigantaba aquella impresión de amenaza inminente. La sola respuesta trágica de sectores medios y altos para con las agitaciones obreras, basados en el acrecentamiento de la sensación de amenaza que provoca la falta de contacto y el aislamiento, permitiría relativizar nuevamente una imagen de ciudad hegemonizada por la vecindad y ciudadanía igualitaria. Sin embargo, volvamos a Lvovich.

En el marco de su hipótesis sobre la semana trágica como "miedo colectivo" inspirado en "teorías del complot" que difundieron el rumor sobre la inminencia de la revolución maximalista por la ciudad (Ibídem: 134), el autor destaca las conferencias antisemitas de curas católicos por algunas de sus esquinas: Corrientes y Junín, Av. Sáenz Peña y Esquiu, Caseros y Rioja (Ibídem: 146). Ya en el cuadro de la huelga en los talleres Vasena, Lvovich sistematiza que, para las cinco de la tarde del 9 de enero, en el centro y Villa Devoto ya corría el rumor de la revolución maximalista en marcha (Ibídem: 153). La columna de obreros -algunos de ellos "armados"- en el sepelio de los primeros cuatro obreros asesinados en la represión, no hacía sino acrecentar el miedo y paranoia. Uno de los hechos que a sus ojos justificaban el temor, y 
que por ende lo hacían aparecer como lógico y razonable, fue el ataque de algunos de los manifestantes a la Iglesia Jesús Sacramentado y al Asilo Casa de Jesús, en Corrientes y Yatay, en Almagro (Ídem). Cerca de Villa Crespo, reducto del maximalismo ruso-judío, podría haber dicho la teoría conspirativa del complot, y todo cerraba.

No sólo los atemorizados y crispados sectores medios-altos veían fantasmas donde no los había: Lvovich retoma los testimonios de quienes vieron a la policía tirando en la oscuridad a una calle vacía (Ibídem: 157), imagen por antonomasia de la lucha contra fantasmas. Estos disparos impactaban en vecinos y transeúntes, sospechosos de ser revoltosos maximalistas. Otro hecho similar fue una información del diario La Prensa de una "intensa y continuada" agresión maximalista contra una comisaría de La Boca, la que, según testimonios contemporáneos, no tuvo igual asidero en los hechos (Ibídem: 158). Sin embargo, como dijimos, la represión fue sintomática, sígnica, indicial: en lugar de atacar donde el dedo apunta, se atacó el dedo apuntador. Retomando la hipótesis de Lvovich, este apuntamiento estaba previamente apuntalado por una emoción paranoica que interpretaba todo nuevo hecho en los términos del esquema cognoscitivo anterior. Entonces el despliegue represivo no se centró exclusivamente en Pompeya sino en lo que consideraban sus entrañas: los barrios donde los judíos-maximalistas se habían asentado en su mayoría, Villa Crespo y Once, más allá de que las ondas expansivas de su conspiración llegaran hasta barrios proletarios como Nueva Pompeya. Dice Lvovich, la persecución fue "específicamente antisemita" (Ibídem: 161). El local de la agrupación judía Poale Zion, en Ecuador 645, el viernes 10 de enero, fue asaltado y destruido; las "habitaciones de los vecinos de la casa" fueron invadidas y destrozadas por el mismo "grupo de particulares armados con revólveres y palos, y encabezados por agentes de policía" (Ibídem: 165). En la esquina de Ecuador y Lavalle, soldados y civiles detuvieron a tres individuos identificados como judíos bajo la imputación de que, cuando vivaban la patria, aquellos abrieron fuego asesinando a uno de ellos, estudiante (Ibídem: 166). La colaboración cívico-militar fue aceitada. Para cerrar el círculo, Lvovich retoma el testimonio en un diario en idish sobre una conferencia antisemita y anticomunista de curas católicos en la esquina de Corrientes y Junín pocos días antes de los sucesos de enero (Ibídem: 178). Para una ciudad reformista e integrada, parece un panorama urbano que relativiza un poco aquella imagen.

\section{Las cartografías}


¿Dónde queda la ciudad de vecinos y ciudadanos en el marco de una "cartografía industrial" (Camarero, 2007: 23) que tiene al obrero -a los obreros, al sujeto clase obrera- como figura central? ¿Es posible compatibilizar figuras ligadas a la propiedad y al reconocimiento abstracto de derechos con otra vinculada al trabajo, a su mundo y padeceres concretos? Entendemos que una posibilidad, en su estudio sobre la inserción del Partido Comunista (PC) en el mundo del trabajo entre fines de la primera guerra mundial y mediados de la década siguiente, estriba en la mención de Camarero del caso del dirigente comunista José Fernando Penelón, escindido del PC en 1928, formando primero el Partido Comunista de la República Argentina (PCRA) y luego Concentración Obrera: como analiza el autor citando a de Privitellio, parte de su reformulación luego de su alejamiento consistió en reinventarse haciendo propias las demandas de sociedades de fomento y reclamos vecinales (Ibídem: XXX). De esta manera, no resultó irreconciliable una identidad comunista e industrial con la recapitulación de soliticitudes vecinales y fomentistas. $\mathrm{O}$, en otra posible alternativa de compatibilización, en el análisis de Camarero de la célula como forma de organización comunista -así como los socialistas y el centro, los radicales y el comité, los peronistas y la unidad básica-, células que contemplaban una "célula de calle" conformada por vecinos de las inmediaciones del establecimiento en cuestión (Ibídem: 6). Ahora, ¿en qué consiste una "cartografía industrial" de la Buenos Aires de entreguerras? ¿Cuál es su utilidad y forma de materialización? La utilidad, entendemos, es otra imagen del corazón político-económico-cultural del país en las primeras tres décadas del pasado siglo, lo cual comporta consecuencias tanto para con un postulado mundo ideal ciudadano e ilustrado, integrado y pos-fraccional, como, inversamente, para con un relato que cifre los comienzos de las clases laboriosas nacionales en la década del 40 . Intentaremos ver el modo de materialización de esta cartografía.

En lugar de ir por fábrica, biblioteca y club, privilegiaremos un enfoque geográfico de modo de intentar acercarnos a la densidad industrial, deportiva y libresca de los barrios. Camarero (Ibídem: 27), en Nueva Pompeya, destaca las dos ya citadas plantas de los talleres Vasena, la manufacturera Establecimientos Americanos Gratry (Ibídem: 31), las bibliotecas Sol de la Humanidad en Fournier 3086 y Albino Arguelles en Guarani 149 (Ibídem: 224), y los clubes Alba Roja en Grito de Asencio 3777 (luego en C. Pagolla 3748 y finalmente en Almafuerte 630), Nex Alumni en Fournier 3086, y Sol de la humanidad primero en la misma dirección del club anterior y luego en Esquiu 1015 (Ibídem: 243).

En Barracas, las plantas fabriles Bunge y Born (Ibídem: 28), la empresa Alpargatas extendiéndose sobre Avenida Patricios desde 1884 (Ibídem: 31), las fábricas de tejidos La 
Nieve, Lacaze y Spiller, y La Unión -luego mudada a Versailles-Liniers- (Ibídem: 32), la biblioteca Federico Engels en Patricios 1698 y el club Ferroviarios del Sud en Salta 2119.

En el vecino barrio de Parque Patricios, otra planta Bunge y Born (Ibídem: 28) -luego mudada a la calle Centenera y disfrazado el nombre de la misma con el de la calle (Ibídem: 29)-, las fábricas de tejidos Breuer, Barlaro, y Bozzalla (Ibídem: 32) y la industria del calzado La Francia Argentina (Ibídem: 36).

En la Boca, las bibliotecas Amigos del comunismo en Suárez 282 y Julio Antonio Mella en Lamadrid 658, y el club Boquense Rojo, primero en Martín Rodríguez 910 y luego en Suárez 282.

En Constitución, la fábrica de tejidos Los Andes (Ibídem: 32) y en el rubro imprenta el Establecimiento Gráfico Argentino (Ibídem: 37), y los clubes La Chispa en Estados Unidos 1056 y luego en Rocha 1599, El martillo y la hoz en Estados Unidos 1056, Justicia en la misma Estados Unidos al 1056 y Enrique G. Müller en Estados Unidos 1525.

En Balvanera, La Siam Di Tella luego mudada a Barracas (Ibídem: 28), los talleres del calzado Andueza, López y Cía, Del Río, y Singer (Ibídem: 36), la planta de elaboración de dulce Tramposlky y de fideos Canessa; Pegassano y Cía. (Ibídem: 32), Camilo Camilloni entre las cristalerías (Ibídem: 38), la biblioteca La Comuna en Moreno 3281, y los clubes Obreros biseladores y anexos en Méjico 2070 -"sede histórica del socialismo de principios de siglo" (Barrancos, 1991: 25)-, Deportivo Metalúrgico en la misma casa, y Obreros gorreros en Boulogne Sur Mer 693. Sólo en este rápido repaso, vemos las diferencias en las elecciones de los nombres de los clubes entre los ideales defendidos -alba roja, sol de la humanidad, la chispa, el martillo y la hoz, justicia- o entre el rubro o rama productiva de sus fundadores ferroviarios del sud, obreros biseladores, deportivo metalúrgico, obreros gorreros-. Las alternativas sin embargo de elección no se restringían a una lógica binaria y dicotómica. Lo veremos a continuación.

En Villa Crespo, vecina a Balvanera, la manufacturera Enrico Dell'Acqua (Camarero, 2007: 34), las fábricas de tejidos Saslov, Laurencio Adot, y Santiago Mutz (Ibídem: 32); Colombo Hnos. y Casa Lapidus y Smud entre la madera y el mueble (Ibídem: 35); Los Vascos, Gaddi e Hijos, y Francisco Bavastro en la industria del calzado, y las tiendas La Federal y Gath y Chaves (Ibídem: 36). Las bibliotecas Germinal en Padilla 794 y Renovación en Canning 871 (luego Vera 587, después Camargo 930). Y los clubes: Germinal (luego Renovación), en las mismas instalaciones de la primera biblioteca -Padilla 794-, El Porvenir en Serrano 851, Renovación en Vera 587 y luego en Camargo 930 -mismo lugar de la segunda biblioteca-, $1^{\circ}$ de mayo de 1886 en Padilla 546, Vorovsky (luego Renovación) en Padilla 794 -mismo sitio tanto de la 
primera biblioteca como del club Germinal, después también Renovación-, Wanders en Huaura 1407, Sapartacus en Camargo 918 y luego Murillo 978; y Avangard primero en Acevedo 659 y después en Gurrruchaga 770.

En Almagro, la planta de elaboración de dulces La perfección (Ibídem: 32), la imprenta M. Orloff (Ibídem: 37), la Compañía Buenos Aires de Ómnibus (Ibídem: 38), la biblioteca Anatole Frano en Bulnes 755 y los clubes Estrella Roja en Billinghurst 139, Industria del mueble en misma dirección (luego Castelli 123), y Luis Recabarren en misma dirección.

En Chacarita, la manufacturera Algodonera Argentina, la Hilandería Argentina, la Fábrica de Tejidos Sedu-Lana (Ibídem: 34) y la curtiembre Ibero Americana (Ibídem: 36).

En Caballito, Mahmud entre las fábricas de tejidos (Ibídem: 32) y La Farmacia Argentina en la industria química (Ibídem: 37), y, en Craig 730, el club Palestra.

En Boedo, la fábrica de tejidos Cayetano Gerli (Ibídem: 31) y la de calzado Negri y Carlino (Ibídem: 32), la biblioteca Trabajo en Garay 3746, y los clubes Sol de mayo en Garay 3746 y Gutenberg en Independencia 4168.

En Paternal, las bodegas y viñedos Ariza, Tomba y Trapiche (Ibídem:33), la Drogrería La Estrella en la industria química (Ibídem: 36), la biblioteca Antorcha de la Verdad en Nicasio Oroño 2211, y el club Compañerito en Nicasio Oroño 2211.

En Flores, la biblioteca Esteban Echeverría primero en Helguera 874 y luego en Argerich 778, y los clubes Eliseo Redus (sin dirección), Claridad en Helguera 447 y Unidos de Flores en Lautaro 1670.

En Palermo, la Cervecería de mismo nombre, la fábrica de bebidas sin alcohol La Bilz (Ibídem: 32), Nordiska en el rubro de la madera y el mueble (Ibídem: 35) y, entre las cristalerías y el vidrio, Picardo (Ibídem: 37).

En Mataderos, La Hispano Argentino (Ibídem: 36) y el club José R. Rodó en J. E. Rodó 7181.

En Devoto, la biblioteca Florentino Ameghino en Pedro Lozano 4047 y el club Salud y Fuerza en Santo Tomé 3911.

Asimismo, Camarero cartografía establecimientos industriales en los barrios de Recoleta -la fábrica de tejidos Bolsalona-, Puerto Madero -los Molinos Rio de la Plata (Ibídem: 32) -, Monserrat -la Droguería Kulemkamppoff Weygand y Cía. (Ibídem: 36)-, San Nicolás -la cristalería Della Penna y Puzzi (Ibídem: 37)- y Villa Pueyrredón -Grafa, primero Textil Sudamericana (Ibídem: 32)-, además de industrias tabacaleras en Villa Urquiza. Y la biblioteca Voltaire en Villa Luro -primero Gaona 6409 y luego en Gaona 6461-.

Por otro lado, y para concluir esta fatigosa pero necesaria sistematización, clubes en: Parque Chacabuco -Unión y trabajo primero en Saruza 927 y luego en Garay 3746; Unión y libertad en 
Saraza 661; $1^{\circ}$ de mayo en Santander 956; Valor y verdad en Cachimayo 1463, y Defensores de Miró en Miró 1350-, en San Cristobal -B. Senra Pacheco en Independencia 2282 e Hijos del pueblo en Danel 1455- y en Liniers -Unión obrera en Byron 6965-.

Cincuenta y nueve fábricas, catorce bibliotecas-centros de autoformación y reunión, cuarenta clubes de fútbol populares, da la imagen de una Buenos Aires que, podía o no ser comunista, pero, industrial, libresca y con una fuerte actividad social, muy verosímilmente. Estos clubes amateurs, agrega Camarero (2007: 241), también eran impulsados por sociedades mutuales y comunidades vecinales. Para 1932, el autor (Ibídem: 252) releva la creación de otros siete nuevos clubes barriales: Sol Naciente en Grivero 3758, Devoto; Gutenberg en Gorriti 4912, Palermo; Amanecer, en Paternal; Aurora, en Almagro; y Naiveth, Discóbolo, y Rojos, en Pompeya. Estos clubes, como los anteriores, se insertaban en experiencias más grandes y aglutinantes como la Federación Deportiva Obrera (FDO), radicada primero en Estados Unidos 1056 y luego en Garay 3746 (Ibídem: 246). La FDO, como los cuarenta y siete clubes antes mencionados, se verán perjudicados y empequeñecidos por la profesionalización y espectacularización (Debord, 1967) del fútbol a comienzos de los 30, dando inicio a la Asociación del Fútbol Argentino y a la hegemonía, desde entonces, de los grandes: River, primero en la Boca y luego en Núñez, y Boca, en el homónimo barrio. La profesionalización del fútbol, más que la construcción de cuerpos y mentes sanas $-\mathrm{y}$, en el caso de los fines del PC, comunistas- y la sociabilización y esparcimiento que el deporte comporta, tenderá a la progresiva empresarización y exclusivización del deporte. El fútbol pasará a ser un deporte espectacular y espectacularizado, que se observa más de lo que se juega.

Otra vía, post-cartografia industrial y deportiva de la Buenos Aires de entreguerras, que el autor brinda para acercarnos a estas dos décadas del centro político del país, es lo que Camarero, en su capítulo sobre "extranjería e internacionalismo en la militancia obrera del PC", llama "subcultura obrera judía" (Ibídem: 302). Ella, fundamentalmente presente en el "gueto abierto" de Once y en el barrio con fuerte presencia judío-polaca de Villa Crespo (Ibídem: 298), se destaca sobre otras colectividades extranjeras del comunismo local: los italianos -habitantes la mitad de ellos en los vecindarios de la primera a la cuarta, y la 15ª , circunscripción (Ibídem: 312)-, los yoguslavos - con fuerte presencia en el maderero y mueblero barrio de Paternal, y en la Boca (lbídem: 318)-, los eslovenos -estimados en veinte mil y dispersos en Paternal, Versailles, Saavedra, Liniers, V. Devoto y V. Real-, y los húngaros -fundamentalmente localizados en la Boca (Ibídem: 319)-.

Los judíos comunistas, en su territorialización urbana, se destacaron por la creación de escuelas obreras judías, organizaciones que las aunaran, así como bibliotecas y/o centros 
culturales. Entre las primeras se destacan las tres escuelas obreras judías en V. Crespo Miriña 1779, Loyola 515 (Ibídem: 302) y Thames 90/92-, las dos en Balvanera -San Luís 2873 y Tucumán 2138-, y las restantes cuatro en: Caballito -Arengreen 1223-, Floresta -Alejandro Magariños Cervantes 3561-, V. Gral Mitre -Trelles 1730 (Ibídem:303)-, y Paternal -Nicasio Oroño 2211 (Ibídem: 302)-. Pero, como decíamos, también se forjaron entidades que las agrupaban e impulsaban: la Arbshulog (Organización de Escuelas Obreras), en Muñecas 1078, Chacarita (Ibídem: 303), y la Farband fin Idishe Folks Shalen (Organización de Escuelas Populares judías) en Olaya 1768, V. Crespo (Ibídem: 305).

Las bibliotecas obreras y centros culturales creados, repasa Camarero, fueron cuatro: la Biblioteca Obrera Israelita en la calle Serrano a la altura de V. Crespo, el Centro Cultural y Biblioteca Obrera Israelita A. Waiter en Nicasio Oroño 2211 -misma sede de la escuela obrera judía de Paternal-, la Biblioteca Obrera Central Israelita en Ayacucho 490 -desde 1906- y la sociedad dramático musical Farvalt-Fraihat en Corrientes 1962. A estas podrían sumarse, en Larrea y Sarmiento, el club Central para Trabajadores y, en Ecuador 473, la Sociedad Obrera Israelita de Socorros Mutuos, las dos en el gueto abierto de Once (Ibídem: 306). Las nueve escuelas obreras judías, las dos organizaciones de nucleamiento y potenciación, y las seis bibliotecas y centros culturales, fundamentalmente en Once y V. Crespo pero asimismo en Paternal, Floresta o V. Mitre, dan cuenta, como al respecto de las cartografías industrial, deportiva y libresca, no sólo de una significativa presencia territorial sino también de un perfil social fuertemente organizativo y colectivo.

\section{La huelga del 36}

El último de los modos en que este trabajo intentará acercarse a la Buenos Aires de entreguerras, a su posconflictividad e integracionismo o bien persistencia de una actitud rebelde y contestataria por parte de las clases laboriosas, será a partir del trabajo de Nicolás Iñigo Carreras (2000) sobre la huelga de la construcción de enero del 36 (3).

Declarada por las pésimas e inhumanas condiciones de trabajo en el sector aludido, el autor da cuenta de su extensión por los barrios de Caballito, Devoto, Villa del Parque, Paternal, V. Crespo, Liniers, Vélez Sarsfield y Flores (Ibídem: 5), a partir del recuento de los puntos urbanos donde mitines-asambleas de organización tuvieron lugar: Av. San Martín y Av. América (hoy Av. Mosconi), Lacarra y Rivadavia, Av. Rivadavia y G. Paz, Canning y Triunvirato (hoy Corrientes), Av. San Martín y Donato Álvarez, Triunvirato y Av. de Los Incas, Cuenca y Pedro 
Lozano (estación Villa del Parque), Yerbal y Fray Cayetano, Rivera (hoy Av. Córdoba) y Dorrego, Almirante Brown y Pedro de Mendoza, Blandengues (hoy Av. del Libertador) y Blanco Encalada, Nazca y Gaona, Rivadavia y Centenera, Rodo y Telles (frente al Matadero), Monteagudo y Av. Derqui (hoy Dellepiane), Monteagudo y Av. Alcorta, Corrientes y Almagro (hoy Acuña de Figueroa), Av. Maipu y Av. Madero, Belgrano y Azopardo, Montes de Oca y California, Boedo y San Juán, Santa Fe y Coronel Díaz y Av. Velez Sarfield y Zepita (Ibídem:167).

La ciudad, el 6 de enero, estaba incendiada de mitines-asambleas discutiendo la declaración y organización de la huelga. Asimismo existían comités de barrio donde persistía la organización de la misma: en V. Crespo -Luís Viale 127-, en Paternal -Trelles 1976-, en P. Patricios Monteagudo 90- y en el centro -Rivadavia 3965- (Ibídem: 168). La huelga declarada para el 7 de enero ya para su mañana contaba con enfrentamientos que, en un punto, se contemplan en la declaración de huelga. El autor refiere la columna de obreros que marchó por Rivadavia desde Liniers hasta Plaza Flores (Ibídem: 175), así como, en un acto de acompañamiento que se encontrará entre los puntos en discusión con posterioridad a la huelga en cuanto al status de aquella compañía, "los piquetes formados espontáneamente por vecinos" al lado de mujeres, jóvenes y niños (Ibídem: 176). Un aspecto interesante de aquella exclusión del vecino es que, en la recorrida policial de comisiones de la Comisaría 39 con posterioridad a los enfrentamientos -nuevamente las relaciones entre policía, vecindad y denuncismo-, la misma sostuvo que las personas que poblaban las calles del barrio no se encontraban entre los agresores de la policía, ya que eran "vecinos de Villa Urquiza" (Iñigo Carreras, 2000: 177). Es decir, según el razonamiento policial, el vecino no puede haber sido el agresor. Este tiene que haber sido externo, exterior, infiltrado, y no una figura de la proximidad, familiaridad e impresión de confianza como la generada por el vecino.

Sin embargo no parece haber sido lo sucedido, sin que ello implique cerrar filas detrás de la interpretación de la emoción de solidaridad hacia los huelguistas de la construcción. Quizá eso sea tan reduccionista como postular la mera ajenidad de todo hecho violento -pedradas, tiroteos, incendios- por parte de los vecinos, así como apelar a hipótesis chivo expiatorias -se trató de niños y adolescentes haciendo travesuras- o a liberales construcciones lebonsianas sobre la animalidad de la masa en oposición a la racionalidad del individuo aislado. No parece haber sido lo sucedido porque, como recuenta Iñigo Carrera, los incendios dejaron de ser una construcción metafórica en torno a la cantidad de mitines-asambleas diseminados por numerosos puntos de la ciudad: volviendo de Urquiza a Villa del Parque, Devoto y Paternal, una panadería en Cesar Díaz y Nazca, un ómnibus en Nazca y Arregui, un camión en Argerich 
y Lescano, un tranvía en Médanos y Nazca, un camión de panadería en Empedrado y San Martín, quemados (Ibídem: 178). En Santo Tomé y Helguera, en Lavallol al 2900, en Av. San Martín y Seguí, en Sanabria y Santo Tomé, en Cuenca y Arregui, en Nazca y Santo Tomé, nuevas quemas y apedreos (Ibídem: 180). Volviendo a Urquiza, se registró un tiroteo en Baunnes entre Cullen y Bebedero (hoy Pedro I. Rivera), así como nuevos intentos de mitinesasambleas en Triunvirato y Canning y Nazca y Páez. En Barragán y Viena, Versailles, así como en la Parada El Talar (hoy Beiró, en el cruce con Nazca), en V. del Parque, otras escaramuzas (Ibídem: 181). Y, para terminar, Iñigo Carrera retoma el testimonio del maquinista del tren que, al pasar por Devoto y Paternal dirigiéndose a Retiro, recibió tiros y piedras (Ibídem: 182), así como, en San Martín y Donato Álvarez, se registraron escenas donde "un grupo de mujeres arengó al vecindario" (Ibídem: 185). Nuevamente la presencia demonizable y sospechosa de la mujer en los enfrentamientos (4). El autor resalta la intensidad de los mismos en los "barrios obreros" de Paternal, V. del Parque, Devoto, Devoto-El Talar, Villa Mitre y Urquiza, lo cual, retrospectivamente, arroja cierta imagen sobre esos vecindarios hoy monoacentuados en su carácter de clase-medieros o distinguidos -principalmente Devoto, V. del Parque y Urquiza-.

Como en la semana trágica, al despliegue huelguístico prosiguió el contraataque estatal y parapolicial. Se detuvieron "en masa manifestantes y vecinos" (Ibídem: 197), lo cual fue contestado por nuevos apedreos en Garibone (hoy Córdoba) y J. Newbery -entre otros (Ibídem: 198)-, y por una nueva asamblea de los huelguistas en la histórica casa de Méjico 2070 (Ibídem:199). La huelga continuó el día 8, pero, luego de la represión, ya nada sería como antes. Como dijimos, al decaimiento de los sucesos huelguísticos sobrevino la interpretación de su carácter, las cuales estuvieron reñidas entre las lecturas anarquistas, comunistas, las de las dos Confederaciones Generales del Trabajo -Independencia 2880, local de la Unión Ferroviaria, y Catamarca 577 (Ibídem: 253)-, y del Partido Socialista en su histórica sede central de la Casa del Pueblo sobre Av. Rivadavia (Ibídem: 263). Entre estos resalta la interpretación del periódico La Vanguardia, donde, citando a su "colega La razón", se lee:

\footnotetext{
Los autores de los hechos de hoy no han sido solamente los participantes del movimiento. Mozalbetes que no hacen nada provechoso sino molestar a transeúntes y vecinos con sus excesos cooperaron a aumentar hechos lamentables escudados por la impunidad que le daban los hechos cometidos por los huelguistas. Estos muchachos dieron clara muestra de su incultura e instintos criminales. La policía llamada por la urgencia de una acción rápida no pudo hacer nada contra esas verdaderas bandas de criminales (Ibídem: 266).
} 
Leído esto, sin determinismo alguno, no cuesta entender interpretaciones que el partido realizará una década después, pero eso es arena de otro costal que excede la Buenos Aires de entreguerras.

\section{Palabras finales}

En este trabajo intentamos un acercamiento a la "teoría de los sectores populares" (Romero, 1988; Gutiérrez y Romero, 1995) a partir de una "cartografía industrial" (Camarero, 2007; 2007a) de la Buenos Aires de entreguerras, que, consideramos, también fue librescabibliotecaria y deportiva. El objetivo fue revisitar una teoría que realiza especial ahínco sobre las ideas de vecino y ciudadano (de Privitellio, 2003). Para realizar aquello, primero repasamos una serie de trabajos (Falcon, 1984; Oved, 1978; Barrancos, 1991; Suriano, 2001; Tarcus, 2007) sobre una de las principales condiciones de producción de la Buenos Aires entreguerrera: el centro político, económico y cultural del país del último cuarto del siglo XIX a la primera década del siglo pasado. Luego, visitamos investigaciones sobre dos de los principales hechos de las dos primeras décadas del siglo XX que asimismo se encuentran entre sus determinantes históricos: las semanas roja (Bilsky, 1985) y trágica (Rock, 1977; Lvovich, 2003). Por último, ya en la Buenos Aires de entreguerras, desgranamos una "cartografía industrial" (Camarero, 2007) como modo de aproximación a una "imagen de ciudad" (Huyssen, 2003) que no resulta precisamente de posconflictividad e integracionismo. En la misma dirección, retomamos un trabajo sobre quizá el principal hecho sindical y gremial de la década del treinta (Iñigo Carrera, 2000), la huelga de la construcción de enero del 36, la cual, desde la gramática de la TSP, de todos modos marcaría el punto final de los veinte años dorados de una cultura popular de perfil no contestatario.

En suma, intentamos retomar trabajos sobre la "teoría de los sectores populares" y la categoría de vecino a partir de una matriz fundamentalmente historicista. Sin que la clara parcelación de campos no sea parte de los problemas de nuestro trabajo académico. En resumen, se trató de volver sobre lo que se considera la politicidad intrínseca de la categoría de vecino y, al fin y al cabo, sobre cuan deseable, teórica y políticamente, resultaría una república de vecinos. Si, como intentamos ver aquí, este significante se mono-acentúa en torno a una abstracta ciudadanía universalista, ¿cuál es el lugar del disenso constitutivo de la acción política? ¿No es precisamente la política la discusión de esa repartición de los lugares sociales? (Ranciére, 
2010) ¿Cuál es la idea de vecino(s) necesaria para composibilizarla con una política de la desidentificación y no de la caratulación policial? Preguntas que este trabajo, lejos de responder, pretendió abrir.

\section{Notas}

(1) Que, en el caso del autor citado, se trata de una "cartografía industrial y comunista" de los barrios de Barracas, La Boca, Nueva Pompeya y Parque Patricios, esos "vecindarios porteños" obreros.

(2) FOA que será FORA (Federación Obrera Revolucionaria Argentina) a partir de 1905 (Suriano, 2001: 17).

(3) El autor, al igual que Camarero (2007a: 38) y a diferencia de Barrancos (1991: 95) y Suriano (2001: 146-217) en su recapitulación de la teoría de los sectores populares, critica elípticamente los postulados de Romero y Gutiérrez afirmando: "en la historiografía argentina se impone hoy como tendencia dominante una pretendida descripción o relato 'aséptico' de los hechos ocurridos, realizada generalmente observando desde el orden establecido, por representantes confesos del liberalismo y apologistas de la sociedad de la primera mitad del siglo XX" (Iñigo Carreras, 2000: 8).

(4) Para un análisis de la construcción mediático-cultural de la(s) mujeres(es) como sospechosa amenaza, ver Huyssen, A. (2006). Después de la gran división. Modernismo, cultura de masas, posmodernismo. Buenos Aires: AH.

\section{Bibliografía}

Barrancos, D. (1991). Educación, cultura y trabajadores (1890-1930). Buenos Aires: CEAL.

Camarero, H. (2007). A la conquista de la clase obrera. Los comunistas y el mundo del trabajo en la Argentina, 1920-1935. Buenos Aires: Siglo XXI.

Camarero, H. (2007a). Consideraciones sobre la historia social de la Argentina urbana en las década de 1920 y 1930: clase obrera y sectores populares. Nuevo Topo. Revista de historia y pensamiento crítico, 4, septiembre-octubre, pp. 35-60.

Debord, G. (1995). La sociedad del espectáculo. Buenos Aires: Biblioteca de la mirada.

De Privitellio, L. (2003). Vecinos y ciudadanos: política y sociedad en la Buenos Aires de entreguerras. Buenos Aires: Siglo XXI.

Falcón, R. (1984). Los orígenes del movimiento obrero (1854-1899). Buenos Aires: CEAL.

Falcón, R. y Montserrat, A. (2000). Estado, empresas, trabajadores y sindicatos. En Falcón, R. (dir.). Nueva Historia Argentina (tomo VI). Democracia, conflicto social y renovación de ideas (1916-1930). Buenos Aires: Sudamericana. 
Gutiérrez, L. y Romero, L. A. (1995). Sectores populares, cultura y política. Buenos Aires en la entreguerra. Buenos Aires: Sudamericana.

Romero, L. A. (1988). Los sectores populares urbanos como sujeto histórico. Buenos Aires: Pehesa-CISEA.

Huyssen, A. (2007). En busca del futuro perdido. Cultura y memoria en tiempos de globalización (Trad. de Silvia Hehrmann). Buenos Aires: FCE.

Huyssen, A. (2006). Después de la gran división. Modernismo, cultura de masas, posmodernismo. Buenos Aires: AH Ed.

Iñigo Carrera, N. (2000). La estrategia de la clase obrera, 1936. Buenos Aires: La Rosa Blindada-PIMSA.

Lvovich, D. (2003). Nacionalismo y antisemitismo en la Argentina. Buenos Aires: Javier Vergara.

Oved, I. (1978). El anarquismo y el movimiento obrero en Argentina. México: Siglo XXI.

Ranciére, J. (2010). En los bordes de lo político (trad. Alejandro Madrid). Buenos Aires: La cebra.

Rock, D. (1977). El radicalismo argentino, 1890-1930. Buenos Aires: Amorrortu.

Suriano, J. (2001). Anarquistas. Cultura y política libertaria en Buenos Aires, 1890-1910. Buenos Aires: Manantial.

Tarcus, H. (2007). Marx en la Argentina. Sus primeros lectores obreros, intelectuales y científicos. Buenos Aires: Siglo XIX. 